\title{
Night eating syndrome among medical students and its correlation with depression in Karachi, Pakistan
}

\author{
Tafazzul Hyder Zaidi', Mubashir Zafar², Rahat Naz', Hiba Farooq ${ }^{1}$, Dania Khan', \\ Maria Jawaid ${ }^{1}$, Kainat Azhar ${ }^{1}$, Fizza Noor ${ }^{1}$, Muhammad Sufiyan' ${ }^{1}$ \\ ${ }^{1}$ Department of Community Medicine, Jinnah Sindh Medical university, Karachi, Pakistan \\ ${ }^{2}$ Family and Community Medicine Department, College of Medicine, University of Hail, KSA
}

\begin{abstract}
Background. Night eating syndrome is common practice in the community. The purpose of this study is to determine the prevalence of night eating syndrome among medical students and its correlation with depression at a public sector medical university in Karachi, Pakistan.

Methodology. It is a cross sectional study and the participants were selected by using multi-stage cluster sampling. Night Eating Syndrome Questionnaire (NES-Q) and Beck depression scale were used to determine the night eating syndrome and depression. Students of age group between 20 and 25 years were included. Comparison of night eating syndrome and depression between groups of students was determined through chi square and Mann-Whitney $\mathrm{U}$ test. Spearmen correlation was used to determine the correlation of night eating syndrome with depression. $P$ value $<0.05$ was considered significant.

Results. The mean age of participants was $21.48 \pm 4.08$ years. Among students $49.36 \%$ and $27.84 \%$ were suffering from night eating syndrome and depression respectively $(p<0.05)$. Students were suffering form night eating syndrome had significantly higher Beck Depression Inventory (BDI) score compared to Non NEQ group with $p$ value 0.03 . A significant correlation was found between night eating syndrome scores and Beck depression inventory scale with $\mathrm{p}$ value was $\leq 0.05$.

Conclusions. Results of this study found that medical students had high prevalence rate of night eating syndrome and depression. Depression was found to be a predictor of night eating syndrome.
\end{abstract}

Keywords: nighttime eating, obesity, medical students, gender

\section{INTRODUCTION}

Night eating syndrome (NES) is a condition which described as evening hyperphagia, nocturnal ingestions, and sleep and mood disturbances (1). Recent studies investigating the impact of pre-sleep nutrient intake have reported negative physiological outcomes in various populations (2). Thus a person with a habit of nighttime eating tends to eat more in the evening (3). This leads to a number of psychological and physical disorders which include obesity, insomnia, hypothalamic disorders, and depression. Apart from these night time eating also causes high blood pressure, high cholesterol and diabetes (4).

Night eating syndrome is associated with some neuroendocrine disorders including decreased plasma concentrations of leptin and melatonin at night (5). This means that the person will tend to eat more at night due to low concentrations of leptin. The patient would also not be able to sleep properly due to low plasma levels of melatonin (6). This is due to alterations in the hypothalamic pituitary adrenal axis which is important for the sleep and awake cycles (7). 
Eating behavior and circadian rhythm are proving to be important factors in the etiology of obesity (8). It is evident that prevalence of night eating syndrome is higher among obese populations than the general community (9). The exact relationship between night eating syndrome and obesity remains unclear (10). Night eating syndrome is found to be common in medical students and it causes weight gain (11). It remains to be determined whether this behavior indicates abnormal sleep patterns lead to nighttime wakefulness and food intake in those prone to weight gain (12).

Night eating syndrome has also been associated with life stress, low self esteem, low mood, depression and related psychopathology (13). Individuals with night eating syndrome who reported nocturnal snacking i.e. waking up from sleep to eat had more severe symptoms than those who did not wake to eat (14). Research also suggested that twenty minutes of muscle relaxation exercise significantly reduced the anxiety, stress and depression among these people (15).

Studies showed that the later a person dines, the more calories he is likely to eat, and the lesser sleeps, he will get depressed (16-17). Less sleep lead to a slower metabolism, and finally weight gain. Experiencing higher levels of stress may lead to night-eating behaviors in medical students (18). They have to cover enormous syllabus in a limited time period, there is sudden change in their style of studying, the thought of appearing or failing in exams leading to stress (19). When we eat late at night those calories are stored as fat which results in weight gain. This could be due to fluctuations in body temperature, biochemical reactions, hormone levels, physical activity and absorption and digestion of food (20). Finally, eating at night can cause acid reflux. Maintaining regular (early) meal timing is important for our health because eating late at night may prompt weight gain (21).

To perform the research on this topic is very much important because this condition is very common and very rare papers were published about it and this condition has many consequences such as loss of appetite at morning, increase appetite at evening and sleep disturbances. The purpose of this research was to explore the night time eating habits among medical students. Medical students are a highly vulnerable group and mainly due to a possi- ble stressful life style. Late night studies can push this group to the habit of late night eating. This research will help the policy makers and institutional heads to formulate student friendly policies as well as the student community to make interventions into their life style. The objective of this study was to determine the prevalence of night eating syndrome and its correlation with depression among medical students in Karachi, Pakistan.

\section{METHODS}

\section{Study setting and participants}

This study was carried out at two public sector medical Colleges in Karachi. Each year, 350 medical students enrolled in each medical college to persue total five years of study regarding medical education. Both male and female students were included in the study.

\section{Study design and sampling technique}

This was the cross-sectional study. The study participants were recruited through multistage cluster sampling, first two clusters were selected then each college sample collected through stratified sampling and within each college participants were selected through simple random sampling. Those students willing to participate in the study were included in the study. The questionnaires were circulated after seeking verbal consent and students were requested to return them within weeks.

\section{Sample size}

Sample size was calculated through World Health Organization Statistical Software for Health Studies. Total 316 students' sample was required to fulfill the objective of the study at $95 \%$ confidence interval, 5\% margin of error and $29 \%$ prevalence of prevalence of night eating syndrome from a previous study (15).

\section{Data collection procedure}

After the approval of respective medical universities' administration, students for each year of respective medical university were approached, briefed about the study objective and self-administered questionnaires were distributed to the students. Participation was voluntary. The content of 
the questionnaire was explained to each participant individually. The questionnaire was returned back after completion by the participants.

\section{Inclusion criteria and exclusion criteria}

The inclusion criteria was the age of the participants from 18 to 26 years who expressed their will to participate in the study. Exclusion criteria for study participants was the case of students who had already been diagnosed and treated for any psychological disorder. Family history of psychological disorders was also excluded. All those who did not give their consent were also excluded.

\section{Data collection tool}

A validated and structured questionnaire was used. The first part included night eating questionnaire (12) to determine the night eating behavior, the second part included back depression inventory to determine the depression and third part included back anxiety inventory to determine the anxiety. These questionnaires were modified after pretesting and developed into a final version. The questionnaire was consisting of four parts namely, student's profile, night eating evaluation, depression and anxiety levels of students. Demographic details of subjects included age, gender, and year of study. Night eating syndrome was assessed by 38 items (13) scales, it consisted of four subscales: restraint, eating concern, weight concern and body shape concern. It is contained 14 questions about symptoms rated on a 5-point Likert-type scale which was then summed up to obtain a NEQ Global Score. A total score $\geq 25$ has been proposed as a lenient threshold for NES. Depression was assessed by 21 items self scale (14). It measured emotional, social, cognitive, and motivational symptoms related to depression. Each of the 21 items on the survey had four statements to be chosen from relating to how the participants felt in the past few days.

\section{Data variables, statistical analysis and ethical consideration}

The dependent variables were night time eating, depression and the independent variable were age, gender, academic year of study, body mass index (BMI) and smoking history of the participants. Data was entered and analyzed in Statistical Pack- age for Social Sciences 20.0 (SPSS, Inc., Chicago, IL, USA). Mean and proportion were calculated for descriptive statistics. Chi-square test was used to determine the difference between night time eating and non-night time eating groups. Mann-Whitney $\mathrm{U}$ test was applied to determine the mean score of night time and non-night time eating groups. Results were recorded as frequencies, means \pm standard deviations (SD), p values. For all purposes, a $p$ value of $<0.05$ was considered as the criteria of significance. Study protocol was approved from the ethical committee of JSMU (IRB-UGS-2020-03064). Informed written consent was taken prior to fill the questionnaire. The participants were assured confidentiality and given option to quit from the study without any further questions and implications.

\section{RESULTS}

Mean age (SD) of study participants was $21.48 \pm 4.03$ years. Most $(75.9 \%)$ of the study participants were female, $68.35 \%$ never smoked in their life, $20.25 \%$ were overweight and $5.44 \%$ obese [Table 1].

Majority (49.36\%) of students were suffering from night eating syndrome. $27.84 \%$ of the participants were suffering from depression. Among night eating syndrome students, $32.05 \%$ were suffering from severe depression [Table 2].

Mean and SD of restraint, eating, weight and shape concern among nighttime eating syndrome affected students were $2.76 \pm 1.23,1.23 \pm 0.87$, $3.45 \pm 1.56$ and $2.98 \pm 1.03$ respectively. Mean and SD of depression among night eating syndrome affected was $19 \pm 3.50$ with $p$ value is 0.03 [Table 3].

Statistically significant correlations between the NEQ and depression scale were found, and some of them were positive correlation as depression increased, so did NES behavior increase. The significant NEQ items included: "How often do you have trouble sleeping at night?" $(\mathrm{r}=0.41, \mathrm{p}=0.05)$, "Other than to use the bathroom, how many times do you wake up in the middle of the night?" $(r=0.21, p=0.002)$, "When you wake up during the night, how many times do you go eat a snack?" $(r=0.29, p=0.003)$, "What is your current level of feeling blue or down in the dumps?" $(\mathrm{r}=0.5$, $p<0.002)$, "What are your cravings to eat when 
TABLE 1. Socio-demographic characteristics among study participants between groups $\left({ }^{* *} N E S\right.$ and Non-NES)

\begin{tabular}{|c|c|c|c|c|c|c|c|}
\hline \multirow[t]{2}{*}{ Characteristics } & \multicolumn{2}{|c|}{ Total $(n=316)$} & \multicolumn{2}{|c|}{ NES $(n=156)$} & \multicolumn{2}{|c|}{ Non-NES $(n=160)$} & \multirow[b]{2}{*}{ p-value* } \\
\hline & $\mathbf{n}$ & $\%$ & $\mathbf{n}$ & $\%$ & $\mathrm{n}$ & $\%$ & \\
\hline Age (years) (mean $\pm S D$ ) & 21.48 & 4.03 & 21.48 & 4.03 & 21.48 & 4.03 & \\
\hline Gender & & & & & & & 0.06 \\
\hline Male & 76 & 24.1 & 51 & 32.69 & 25 & 15.62 & \\
\hline Female & 240 & 75.9 & 105 & 67.31 & 135 & 84.38 & \\
\hline Academic year of study & & & & & & & 0.04 \\
\hline First year & 7 & 2.2 & 3 & 1.92 & 4 & 2.5 & \\
\hline Second year & 35 & 11.1 & 10 & 6.41 & 25 & 15.62 & \\
\hline Third year & 59 & 18.7 & 18 & 11.53 & 41 & 25.62 & \\
\hline Fourth year & 175 & 55.4 & 95 & 60.89 & 80 & 50 & \\
\hline Fifth year & 40 & 12.7 & 30 & 19.23 & 10 & 6.25 & \\
\hline Smoking & & & & & & & 0.05 \\
\hline Ever & 100 & 31.65 & 56 & 35.89 & 44 & 27.5 & \\
\hline Never & 216 & 68.35 & 100 & 64.11 & 116 & 72.5 & \\
\hline Body Mass Index (BMI) & & & & & & & 0.03 \\
\hline Underweight (BMI $\leq 18.5$ ) & 30 & 9.44 & 10 & 6.41 & 20 & 12.5 & \\
\hline Normal (BMI 18.5-24.9) & 205 & 64.87 & 86 & 55.12 & 119 & 74.37 & \\
\hline Overweight (BMI 25-29.9) & 64 & 20.25 & 50 & 32.05 & 14 & 8.75 & \\
\hline Obese $(\mathrm{BMI} \geq 30)$ & 17 & 5.44 & 10 & 6.41 & 7 & 4.37 & \\
\hline
\end{tabular}

TABLE 2. Prevalence of nighttime eating and depres-

sion among study participants $(n=316)$

\begin{tabular}{|l|c|c|}
\hline Characteristics & Frequency ( $\mathbf{n})$ & Proportion (\%) \\
\hline Normal Eating* & 160 & 50.64 \\
\hline $\begin{array}{l}\text { Nighttime Eating Syndrome } \\
\text { (NEQ Global Score >25) }\end{array}$ & 156 & 49.36 \\
\hline Depression & 88 & 27.84 \\
\hline $\begin{array}{l}\text { Depression in NES group } \\
\text { ( } \mathbf{n = 1 5 6 )}\end{array}$ & 50 & 32.05 \\
\hline
\end{tabular}

*NEQ scale (0-25 = normal, > 25 = nighttime eating syndrome)

TABLE 3. Comparison of eating disorder symptomatology and psychosocial health between study participants $(n=316)$

\begin{tabular}{|l|c|c|c|c|c|c|c|}
\hline & \multicolumn{2}{|c|}{ Total Sample (n = 316) } & \multicolumn{2}{c|}{ NES (n= 156) } & \multicolumn{2}{c|}{ NON-NES (160) } & \\
\hline EDE-Q & Mean & SD & Mean & SD & Mean & SD & P value* \\
\hline Restraint & 1.66 & 1.03 & 2.76 & 1.23 & 1.11 & 0.87 & 0.04 \\
\hline Eating & 1.32 & 1.07 & 1.23 & 0.87 & 1.29 & 1.02 & 0.05 \\
\hline Shape & 1.98 & 0.98 & 3.45 & 1.56 & 1.87 & 1.67 & 0.04 \\
\hline Weight & 1.56 & 0.95 & 2.98 & 1.03 & 1.23 & 1.1 & 0.02 \\
\hline Global & 1.43 & 1.04 & 2.34 & 1.08 & 1.38 & 1.15 & 0.01 \\
\hline BDI Scale & 8 & 2.5 & 19 & 3.5 & 13 & 2.1 & 0.03 \\
\hline
\end{tabular}

*Mann Whitney $\mathrm{U}$ test, $\mathrm{BDI}=\mathrm{Back}$ depression inventory scale, EDE-Q= eating disorder examination questionnaire

you wake up at night?" $(\mathrm{r}=0.19, \mathrm{p}<0.005)$, and "When you wake up at night, do you feel the need to eat before you can fall back to sleep?" $(\mathrm{r}=0.65$, $\mathrm{p}=0.03)$. A significant correlation was also found between Beck Depression Inventory scores and NEQ scores $(r=0.74, p=0.012)$ [Table 4].

Distribution of all subjects with NES was done according to BMI category. Across five BMI categories the prevalence of NES increased as BMI increased, and was found to be statistically different between the groups $(\mathrm{P}=0.001)$ [Figure 1].

\section{DISCUSSION}

Night eating syndrome was common among medical students and depression was also high in prevalence among night eating syndrome group. This study found that depression was one of the 
TABLE 4. Correlations of Beck depression inventory scores with night eating syndrome items scores $(n=316)$

\begin{tabular}{|l|c|c|c|c|}
\hline Night eating syndrome items & M & SD & $\begin{array}{c}\text { Correlations with Beck } \\
\text { depression inventory } \\
\text { total scores (r) }\end{array}$ & p value \\
\hline Morning appetite & 2.62 & 1.01 & -.08 & 0.030 \\
\hline First meal of day & 1.41 & 0.21 & -.02 & 0.011 \\
\hline $\begin{array}{l}\text { Percentage of calories consumed after } \\
\text { supper }\end{array}$ & 1.38 & 0.19 & -.05 & 0.051 \\
\hline Trouble sleeping & 1.56 & 0.05 & .41 & 0.052 \\
\hline Number of times per night awake & 1.12 & 0.31 & .21 & 0.021 \\
\hline Number of times per night snacking & 0.12 & 0.01 & .29 & 0.031 \\
\hline Level of awareness & 4.96 & 1.2 & -.01 & 0.061 \\
\hline Level of feeling blue & 1.85 & 0.15 & .59 & 0.022 \\
\hline Time of day when mood is lowest & 1.9 & 1.21 & -.07 & 0.041 \\
\hline Cravings or urges to eat after supper & 2.2 & 1.01 & .19 & 0.051 \\
\hline Cravings to eat when wake up at night & 0.77 & 0.2 & -.02 & 0.021 \\
\hline Need to eat to fall back asleep & 0.23 & 0.1 & .65 & 0.032 \\
\hline Control over night eating & 0.54 & 0.09 & -.15 & 0.011 \\
\hline Nighttime eating syndrome (Global score) & & & 0.74 & 0.012 \\
\hline
\end{tabular}

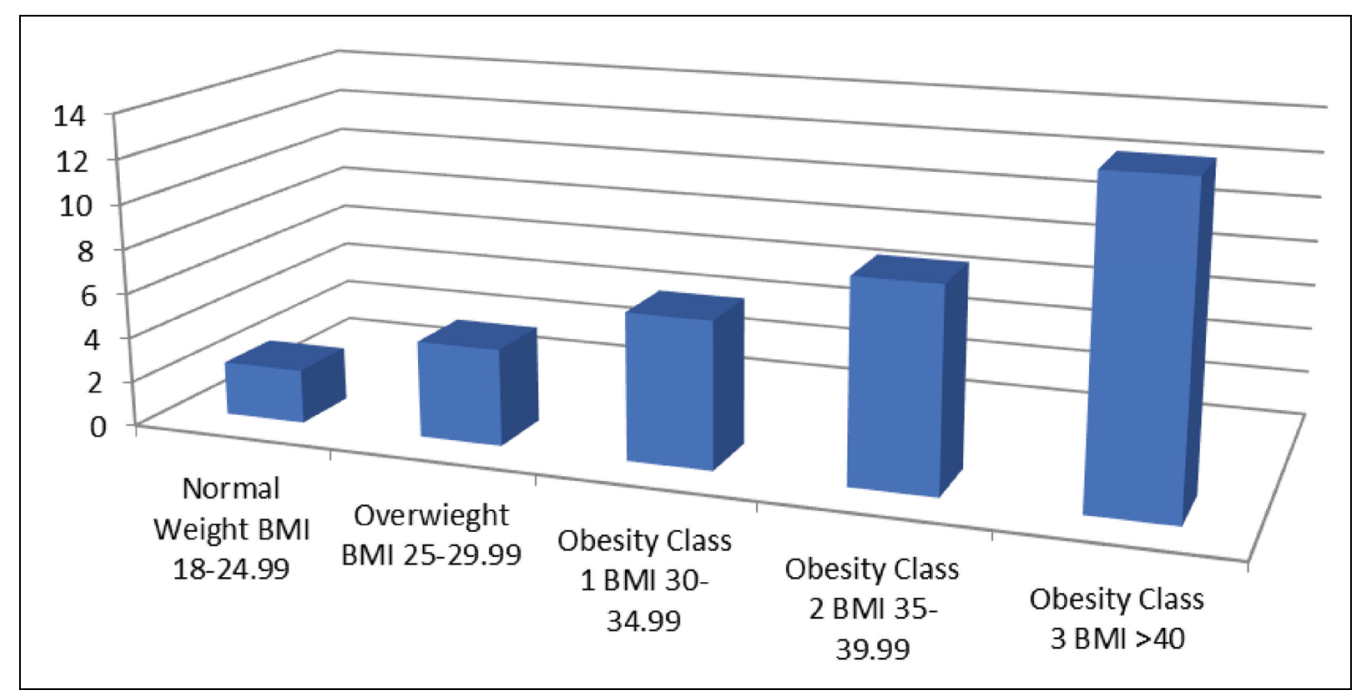

FIGURE 1. Distribution of all subjects with NES, according to BMI category

factor which led to nighttime eating syndrome. The result of study also found that body mass index increased as NES increased.

The result of the study found that $49.36 \%$ of students were suffering from NES and this prevalence was higher than general population which was found to be $30 \%(22)$. In a study conducted in the US in 2014 to find out the prevalence of night time eating among university students showed that only $4.2 \%$ of the students were suffering from night eating syndrome (23). Thus, it can be interpreted that night time eating is much more common among medical students of Pakistan as compared to the US.
This study found that the frequency of first year medical students who indulged in night eating was $1.92 \%$. However, this percentage was higher to $60.89 \%$ in fourth year medical students. These results are in consistence with other another study results which show that as the academic year is increased the NES is also increased (24).

According to our study, $67.31 \%$ of the total number of females were suffering from NES. The prevalence of night eating syndrome in male medical students was found to be $32.69 \%$ which meant that females tended to night time eating much more compared to males. However, in a study conducted 
in the US among students, only $20.6 \%$ of the women suffered from night eating syndrome (25). From this we can interpret that female medical students in Karachi tended to have food at night more than males' medical students.

In this study, $20.25 \%$ were medical students were overweight and $5.44 \%$ were obese. Among overweight students, $32.05 \%$ were suffering from NES. This study results were consistent with other study results (26). This shows that students well aware of the fact that night eating syndrome leads to obesity as discussed in a research that was previously conducted that night eating syndrome was positively associated with BMI (26).

This study showed that depression was common (27.84\%) among NES students' groups. This result is consistent with other study results (27). The association between NES and depressive symptoms has been verified in several studies (27-29). A previous study reported that $75 \%$ of the depressed students were NES diagnosed (30).

This study results found that there was a significant correlation $(r=0.65, p=0.03)$ between NES with other study results which shows that revealed a substantial correlation between NEQ and depresand depressive symptoms. These results are similar

sion scores among students. A study showed that depression might be a confounding factor on the relationship between NES and depression (31).

Our study findings show that as BMI increase the NES is also increased. This result is also confirmed with other study results (32) Another study found that those participants who had NES had most likely increased BMI (32-33).

There were several limitations of our study results. First it was the cross-sectional study which cannot determine the temporal relationship. Second there were several confounding factors such as late time sleep, late time eating and skipping morning eating are all attributes of university students that may confound the findings. Third, the data is self-reported and there is information bias in the study.

\section{CONCLUSIONS}

This study found that high prevalence of night eating syndrome among medical students in Karachi and that depression is the important predictor for night eating syndrome. Spreading its awareness especially in the medical education institutions is something that needs to be addressed.

Conflict of interest: none declared Financial support: none declared

\section{REFERENCES}

1. Erskine HE. Whiteford HA. Pike KM. The global burden of eating disorders. Current Opinion Psychiatry. 2016;29(6):346-53.

2. Kinsey A, Ormsbee MJ,. The Health Impact of Nighttime Eating: Old and New Perspectives. Nutrients. 2015;7(4):2648-2662.

3. Gluck ME, Geliebter A, Satov T. Night eating syndrome is associated with depression, low self esteem, reduced daytime hunger, and less weight loss in obese outpatients. Obesity Research. 2001;9(4):264-7.

4. Staels B. When the Clock stops ticking, metabolic syndrome explodes. Nature. 2006;12(1):53-5.

5. Striegel Moore RH, Rosselli F, Perrin N, DeBar L, Wilson GT, May A, et al. Gender difference in the prevalence of eating disorder symptoms. International Journal of Eating Disorders. 2009;42(5):471-4.

6. Stunkard AJ, Grace WJ, Wolff HG. The night-eating syndrome: A pattern of food intake among certain obese patients. The American Journal of Medicine. 1955;19(1):78-86.

7. Colles S, Dixon J, O'brien P. Night eating syndrome and nocturnal snacking: Association with obesity, binge eating and psychological distress. International Journal of Obesity. 2007;31(11):1722-30.

8. Striegel Moore RH, Franko DL, Thompson D, Affenito S, Kraemer HC. Night eating: Prevalence and demographic correlates. Obesity. 2006;14(1):139-47.

9. Gallant A, Lundgren J, Drapeau V. The night eating syndrome and obesity. Obesity Reviews. 2012;13(6):528-36.

10. Gluck ME, Venti CA, Salbe AD, Krakoff J. Nighttime eating: commonly observed and related to weight gain in an inpatient food intake study. The American Journal of Clinical Nutrition. 2008;88(4):900-5.

11. Birketvedt GS, Sundsfjord J, Florholmen JR. Hypothalamic-pituitaryadrenal axis in the night eating syndrome. American Journal of Physiology-Endocrinology and Metabolism. 2002;282(2):E366-E9.

12. Bose $M$, Oliván $B$, Laferrère $B$. Stress and obesity: the role of the hypothalamic-pituitary-adrenal axis in metabolic disease. Current opinion in endocrinology, diabetes, and obesity. 2009;16(5):340.

13. Gluck ME, Geliebter A, Satov T. Night eating syndrome is associated with depression, low self-esteem, reduced daytime hunger, and less weight loss in obese outpatients. Obesity Research. 2001;9(4):264-7.

14. Colles SL, Dixon JB, O'brien PE. Night eating syndrome and nocturnal snacking: association with obesity, binge eating and psychological distress. International Journal of Obesity. 2007; 31(11):1722-30.

15. Pawlow LA, O'neil PM, Malcolm RJ. Night eating syndrome: effects of brief relaxation training on stress, mood, hunger, and eating patterns. International Journal of Obesity. 2003;27(8):970-8.

16. Wichianson JR, Bughi SA, Unger JB, Spruijt-Metz D, Nguyen Rodriguez ST. Perceived stress, coping and night eating in college students. Stress and Health. 2009;25(3):235-40.

17. Ray I, Joseph D. Stress in medical students. JK Science. 2010; 12(4):163-4.

18. Birketvedt GS, Florholmen J, Sundsfjord J, Østerud B, Dinges D, Bilker W, et al. Behavioral and neuroendocrine characteristics of the night-eating syndrome. JAMA. 1999;282(7):657-63. 
19. Cleator J. Abbott J. Judd P. Sutton C. Wilding JPH. Night eating syndrome: Implications for severe obesity. Nutr Diabetes. 2012; 2(9):e44.

20. Goel N. Stunkard AJ. Rogers NL. Van Dongen HP. Allison KC. O'Reardon JP. et al. Circadian rhythm profiles in women with night eating syndrome. J Biol Rhythms. 2009;24(1):85-94.

21. Marshall HM. Allison KC. O'Reardon JP. Birketvedt G. Stunkard AJ. Night eating syndrome among nonobese persons. Int $\mathrm{J}$ Eat Disord. 2004; 35(2):217-22.

22. Zadjali F, Al-Bulushi A, AlHassani F, Al Hinai M. Proportion of night eating syndrome in Asian population. J Eat Disord. 2015;3:43.

23. Nolan LJ, Geliebter A. Night eating is associated with emotional and external eating in college students. Eat Behav. 2012;13:202-6.

24. Lund HG, Reider BD, Whiting AB, Prichard JR. Sleep patterns and predictors of disturbed sleep in a large population of college students. J Adolesc Health. 2010;46:124-32.

25. Cooley E, Toray T, Valdez N, Tee M. Risk factors for maladaptive eating patterns in college women. Eat Weight Disord. 2007;12:132-9.

26. Aronoff NJ, Geliebter A, Zammit G. Gender and body mass index as related to the night-eating syndrome in obese outpatients. J Am Diet Assoc. 2001;101:102-104.
27. Thompson SH. DeBate RD. An exploratory study of the relationship between night eating syndrome and depression among college students. J Coll Stud Psychother. 2010;24:39-48.

28. Küçükgöncü S, Beştepe E. Night Eating Syndrome in Major Depression and Anxiety Disorders. Arch Neuropsychiatr. 2014;51:368-75.

29. Gluck, M. E., Geliebter, A., \& Satov, T. Night eating syndrome is associated with depression, low self-esteem, reduced daytime hunger, and less weight loss in obese outpatients. Obesity Research. 2001;9:264-267.

30. Wichianson JR. Bughi SA. Unger JB. Spruijt-Metz D. Nguyen-Rodriguez ST. Perceived stress. coping and night-eating in college students. Stress and Health. 2009; 25(3):235-40.

31. Striegel-Moore RH, Franko DL, May A, Ach E, Thompson D, Hook JM. Should night eating syndrome be included in the DSM? International Journal of Eating Disorders. 2006;39(7):544-549.

32. Stunkard AJ. Night eating syndrome. In Fairburn CG \& Brownell KD (Eds.), Eating disorders and obesity: A comprehensive handbook (2nd ed., pp. 183-187). 2002. New York: The Guilford Press.

33. Tholin $S$, Lindroos A, Tynelius $P$, et al. Prevalence of night eating in obese and nonobese twins. Obesity. 2009;17:1050e5. 